\title{
Recovery Room: Safety Island in the Operating Theatre
}

\author{
Dmitriy Staroverov*, Feruza Ismailova \\ Department of Anaesthesia, University Teaching Hospital, Lusaka, Zambia
}

\section{INTRODUCTION}

The immediate postoperative period (first 24 hours) is a time when surgical patients undergo many significant changes. It is a period of vulnerability even for a relatively healthy patient. Studies of anesthetic morbidity and mortality have identified the immediate postoperative period as a time when patients are at significant risk of experiencing anesthetic and/or surgical complications. ${ }^{1,2,3}$. A number of publications show clearly that approximately $10 \%$ of all anesthetic accidents occur in the recovery period. ${ }^{4}$

Before 1950's, patients were usually cared for in an ill-defined postoperative unit or on the hospital ward. Patients were frequently transferred from the operating room directly to the ward where they were placed close to the nursing station. In 1947 the Anesthesia Study Commission of the Philadelphia Country Medical Society published the results of an 11-year study of anesthetic mortality. They concluded that nearly one third of the anesthetic deaths were a result of inadequate postoperative monitoring. These finding, along with a critical nursing shortage, stimulated widespread development of recovery rooms.

This article summarizes recent information about recovery area and describes modern discharge criteria from the recovery room.

\footnotetext{
*Corresponding Author:

Dmitriy Staroverov

Department of Anaesthesia,

University Teaching Hospital

P.O Box 50001, Lusaka, Zambia

Email:dmitriystaroverov@yahoo.com.au
}

\section{BASIC PRINCIPLES}

\section{Location}

It is clear that the recovery room should occupy a central area within the operating suite, as far as possible equidistant from all the theatres and to the intensive care unit. As well as minimizing transfer times, this also means that recovery staff will have more ready access to expert anesthetic help.

\section{Design}

Some recent recommendations from the NHS Agency of the Department of Health (in the UK) assert that the ratio of beds to operating theatres should be not less than two, and that a suite of eight theatres should have a total floor space of $164 \mathrm{~m}^{2,6}$.

The recovery bays should be matched for purpose. There should be curtains or screen to allow privacy, and where possible there should be separation of the sexes. This is rarely done (to provide this privacy just double the space will be enough), moreover, it is commonplace to have a designated area for children. Such an area should be decorated appropriately and should allow access to parents.

Common sense dictates that any design should incorporate adequate storage, a dirty utility area, washing facilities, adequate provision of electrical outlets and desk space for clerical tasks.

Each bay should have pipeline outlets for oxygen, air and suction.

\section{Equipment}

Potential post-anesthetic and surgical problems mean that there must be immediate access to the some drugs and equipment, both standard and emergency, as are available in the anesthetic room and operating theatre. The standard equipment requirements to the recovery room are set out in Table 1. 
Table 1. Standard equipment requirements for the recovery room

\begin{tabular}{|l|}
\hline $\begin{array}{c}\text { - oxygen supplementary system (centrally or oxygen } \\
\text { concentrators) }\end{array}$ \\
\hline - oropharyngeal and nasopharyngeal airways \\
\hline $\begin{array}{c}\text { - laryngoscopes (adult and children) - a wide range } \\
\text { of endotracheal tubes and laryngeal masks }\end{array}$ \\
\hline - cricothyroidotomy puncture kits \\
\hline - 1 ventilatory apparatus (for 5 beds) - 1 anesthetic \\
machine to quickly anesthetize a patient if need be \\
(for 5 beds)
\end{tabular}

\section{Staffing}

There should be sufficient trained staff to allow continuous one-to-one care of every patient passing through the recovery unit. Ideally this would be a named individual with responsibilities only to the patients' recovery. Usually the requirement of nursing care in the postanesthetic phase accounts for 1 nurse/1 postoperative patient.

The particular skills of the staff will vary according to the case mix of the surgical unit, but their core skills should include basic airway management, immediate life support, and the ability to assess accurately a patient's cardiac, respiratory and volaemic status.

\section{Transport}

Care of the postoperative patient begins in the operating theatre when the patient is transferred to the trolley (gurney) for transport. Every transport from the theatre is carried under direct supervision of the anesthetist or anesthetic clinical officer. Patients should be transported in the lateral decubitus position to maximize airway patency and to help prevent aspiration unless they are wide awake. Supplementary oxygen via facemask is indicated in most patients to prevent hypoxemia due to hypoventilation or diffusion hypoxia. During transport to the recovery area, the patient must be observed for evidence of vomiting or airway obstruction secondary to the accumulation of blood or secretion in the pharynx.

\section{Handover}

It is standard practice for a member of the theatre team (usually, a scrub nurse) to convey operative information such as details of the surgical procedure and the presence of any drains or other devices. The anesthetist, who should have accompanied the patient to the recovery room, should supplement this with a brief verbal summary detailing any other relevant information. This handover should include any perioperative surgical or anesthetic complications or interventions that might influence recovery, as well as any pre-existing medical condition that may be of significance (asthma, epilepsy, mild dementia, etc).

\section{COMPLICATIONS IN THE RECOVERY ROOM}

The incidence of recovery area complications varies with the patient population and appears to be more common in patients with mild or moderate coexisting diseases. Some studies have been showed that complications causing at least moderate morbidity occur in approximately $2.5-30 \%$ of the recovery room admissions. ${ }^{8,9,10}$ The most frequent complications in the recovery room are described in the Table 2.

Table 2. The most common complication occurring in the recovery room.

- arterial hypotension due to hypovolemia, impaired venous return, vasodilation

- arterial hypertension due to pre-existing hypertensive disease, pain, fluid overload, hypercarbia, urine bladder distension, increased intracranial pressure (ICP)

- dysrhythmias due to hypoxemia, hypercarbia, electrolyte disturbances, increased sympathetic outflow, increased ICP, drug toxicity

- hypoxemia due to atelectasis, hypoventilation, diffusion hypoxia, upper airway obstruction, bronchospasm, aspiration of gastric contents, pulmonary edema, pneumothorax, embolism

- hypoventilation due to decreased ventilatory drive, pulmonary and respiratory muscle insufficiency

- upper airway obstruction due to incomplete recovery, laryngospasm, airway edema, vocal cord paralysis, wound hematoma 


\begin{tabular}{l}
\hline - delayed awakening due to persistent effects of \\
anesthetics, decreased cerebral perfusion, metabolic \\
causes (hypothermia, hypoglycemia, electrolyte and \\
acid-base derangements) \\
\hline - postoperative nausea and vomiting \\
\hline
\end{tabular}

\section{DISCHARGE CRITERIA}

Before discharge, a surgical patient who has undergone anesthesia should meet certain criteria. The modified Aldrete score is a simple sum of numerical values assigned to activity, respiration, circulation, consciousness, and oxygen saturation (see Table 3). ${ }^{11}$

The Post Anesthesia Discharge Scoring System modifies these required parameters by including assessment of pain, nausea/vomiting, and surgical bleeding in addition to vital signs and activity (see Table 4). ${ }^{12}$

Despite any criteria, the anesthetist should see the patient again before being discharged from the recovery area and the patient's condition should be recorded in the medical file.

Table 3. Postanesthesia Recovery Score (Modified Aldrete Score)

\begin{tabular}{|l|}
\hline Activity \\
\hline $2=$ Moves all extremities voluntarily/on command \\
\hline $1=$ Moves two extremities $0=$ Unable to move limbs \\
\hline Respiration \\
\hline $2=$ Breathes deeply and coughs freely \\
\hline $1=$ Dyspneic, shallow or limited breathing \\
\hline $0=$ Apneic \\
\hline Circulation \\
\hline $2=\mathrm{BP}+20 \mathrm{~mm} \mathrm{Hg}$ of preanesthetic level \\
\hline $1=\mathrm{BP}+25-50 \mathrm{~mm}$ Hg of preanesthetic level \\
\hline $0=\mathrm{BP}+55 \mathrm{~mm} \mathrm{Hg}$ of preanesthetic level \\
\hline Consciousness \\
\hline $2=$ Fully awake \\
\hline $1=$ Arousable on calling \\
\hline $0=$ Not responding \\
\hline Oxygen Saturation \\
\hline $2=$ SpO2 $92 \%$ on room air \\
\hline $1=$ Supplemental oxygen required to maintain $\mathrm{SpO} 2$ \\
\hline
\end{tabular}

\begin{tabular}{|l|}
\hline$>90 \%$ \\
\hline $\begin{array}{l}0=\mathrm{SpO} 2 ? 92 \% \text { with oxygen supplementation } 10= \\
\text { total score }\end{array}$ \\
\hline Score $>9$ required for discharge \\
\hline
\end{tabular}

Table 4. Postanesthesia Discharge Scoring System

\begin{tabular}{|l|}
\hline Vital signs (BP and heart rate) \\
\hline $2=$ Within $20 \%$ of preoperative baseline \\
\hline $1=21-40 \%$ of preoperative baseline \\
\hline $0=>40 \%$ of preoperative baseline \\
\hline Activity $2=$ Steady gait, no dizziness \\
\hline $1=$ Requires assistance $0=$ Unable to ambulate \\
\hline Nausea and Vomiting \\
\hline $2=$ Minimal: treat with per os medications \\
\hline $1=$ Moderate: treat with IM medications \\
\hline $0=$ Continues: repeated treatment \\
\hline Pain \\
\hline Acceptable to patient; control with per os medications \\
\hline $2=$ Yes \\
\hline $1=$ No \\
\hline Surgical bleeding \\
\hline $2=$ Minimal: no dressing change required \\
\hline $1=$ Moderate: up to 2 dressing changes \\
\hline $0=$ Severe: more than 3 dressing changes \\
\hline $10=$ maximum score \\
\hline Score $>9$ required for discharge \\
\hline
\end{tabular}

\section{SUMMARY}

The current surgical interventions have become complicated all over the world. In order to provide these needs contemporary anesthesiology offers various complex anesthetic techniques, drugs for ensuring adequate anesthetic managements. According to this principle it seems obviously that further development of the recovery room service is essential. Patients' safety at every level of hospital stay (ward-operating theatre-recovery room-ward) should be organized. It's logically to assume the recovery room should have been adjusted, comfortable and dynamic for competent management of the surgical patients in the postoperative period. 


\section{REFERENCES}

1. Cohen MM, Duncan PG, Pope WDB et al. A survey of 112,000 anaesthetics at one teaching hospital. Can J Anaesth 1986; 33: 22.

2. Lunn JN, Hunter AR, Scott DB. Anaesthesiarelated surgical mortality. Anaesthesia 1983;38: 1090.

3. Tiret L, Desmonts JM, Hatton $F$ et al. Complications associated with anaesthesia a prospective survey in France. Can J Anaesth 1986; 33: 336.

4. Van Aken H, Vandermeersch E. Postanesthetic care unit (P.A.C.U.). A necessity for every hospital. Acta Anaesthesiol Belg. 1990; 41(1): 36.

5. Ruth HS, Haugen FP, Grave DD. Anesthesia Study Commission: findings of eleven years of activity. JAMA 1947; 135: 881.

6. Immediate postanaesthetic recovery. Association of Anaesthetists of Great Britain and Ireland. September 2002.
7. Diaconescu D, Grecu L. Chapter 35: The postanesthesia care unit. In: Dunn PF (eds). Clinical Anesthesia Procedures of the Massachusetts General Hospital. Lippincott Williams \& Wilkins, 2007: 624.

8. Leykin Y, Costa N, Gullo A. Recovery Room. Organization and clinical aspects. Minerva Anestesiol 2001; 67(7-8): 539-554.

9. Khan FA, Soomro NA, Kamal RS. A review of 6978 consecutive admissions to the recovery room at a university hospital. $J$ Pak Med Assoc 1991; 41(1):2-6.

10. Norsidah AM, Puvaneswari A. Anaesthetic complications in the recovery room. Singapore Med J. 1997; 38(5): 200-204.

11. Feeley TW, Macario A. Chapter 71: The postanesthesia care unit. In: Miller RD (eds). Miller's Anesthesia, $6^{\text {th }}$ edition (volume two). Elsevier Churchill Livingstone, 2005: 2709.

12. Chung F, Chan VW, Ong D. A post-anesthetic discharge scoring system for home readiness after ambulatory surgery. J Clin Anesth 1995; $7: 500$. 